POLIIICAL ECONOMY RESEARCH INSIITUTE

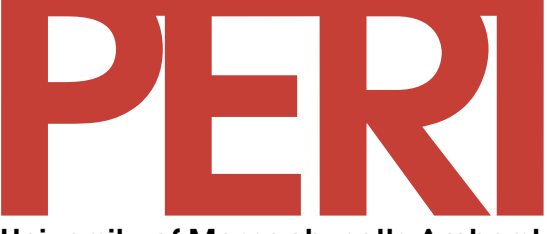

University of Massachusetts Amherst

\title{
A more or less unequal world? World income distribution in the 20th century
}

\author{
Bob Sutcliffe
}

2003

10th floor Thompson Hall University of Massachusetts Amherst, MA, 01003-7510 Telephone: (413) 545-6355 Facsimile: (413) 545-2921

Email:peri@econs.umass.edu Website:

hHp://www.umass.edu/peri/

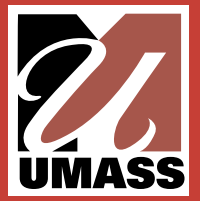




\title{
A more or less unequal world? World income distribution in the 20th century
}

\author{
Bob Sutcliffe \\ (Hegoa and Department of Applied Economics I, University of the Basque Country, \\ Bilbao), November $2002^{1}$
}

\footnotetext{
${ }^{1}$ My thanks to Andrew Glyn for many helpful comments on this paper
} 


\section{Contents}

1. Partial evidence about the poor and the rich

2. What to measure: integral measures versus ratios of groups

3. How to compare incomes: exchange rates versus purchasing power parity

4. Difference sources of ppp income data

5. Inter-country versus global distribution

6. Difference sources of distribution data

7. Inter-country studies compared

8. Global studies compared

9. Two additional calculations

10. More disaggretated measures

11. Agreements and disagreements

12. Ironies of the debate 
Statistical studies are hardly needed to prove the existence of immense material inequality between human beings. It is evident to anyone who walks down the street in most major cities or watches a television newscast which jumps from images of famine in Angola to the business or the football transfer news. This article takes the existence of great inequality as given but discusses the various ways in which that inequality can be and is measured and surveys evidence about how inequality on a world scale has evolved during the last century and especially since 1980.

\section{Partial evidence about the poor and the rich}

According to the World Bank's frequently quoted figures, 56 percent of the world's population were living below the poverty line of $\$ 2$ a day in 1998 . This estimate is based on household surveys conducted between 1985 and 1998, the results being compared using purchasing power parity prices of 1993 and the figures updated in accordance with aggregate consumption figures. This means that in countries where income has become more unequally distributed this method will underestimate the number of poor people (and vice versa). The latest calculations estimate that both the poverty and the extreme poverty ( $\$ 1$ a day) rate have fallen during the years 1987-1998 (from 61 per cent to 56 per cent and from 28 to 23 per cent respectively) but that the absolute numbers of poor people grew during this period by about 260 millions (World Bank 2001). While the Bank's estimates are evidence that poverty is the norm for around half of the world's population it is not easy to use them in the form in which they are published. This is because they do not give estimates of incomes but only of the numbers of people living below a given level of income; and they provide no information about the incomes of those who are not poor. The kind of household survey data on which they are based, however, will be seen later in this article to play a central role in reaching quantitative estimates of inequality on a world scale.

We know less about the very rich and their income. This is partly because they are able to hide their wealth and partly because fewer research resources are devoted to studying extreme wealth since it is not officially regarded as socially pathological. In some countries, however, surveys of the relative incomes of the rich have been conducted. In the United States, for instance, it is estimated that between 1960 and 1999 the average real pay of chief executive officers of large corporations rose by 11 times while that of real production workers remained almost unchanged (Sutcliffe 2001, derived from data on EPI website). Forbes magazine and various other publications regularly list the very wealthy of the world and a group of financial companies has recently started to produce an annual World Wealth Report (Merrill Lynch and Cap Gemini Ernst \& Young 2002). While this estimates that in the year 2001 there were 7.1 million people in the world with assets of more than one million dollars ('high net-worth individuals' or HNWIs) and that these owned \$26.2 trillion in assets, it provides no estimates of their incomes. Such information contributes even less to estimating the overall worldwide distribution of income than that the available information on the poor.

Yet, when we place such disparate information together, although it is only a few pieces of the jigsaw, a picture of extreme and possibly rising inequality is suggested. Facts of 
this kind have fed a conviction, almost universal among journalists and political critics of the status quo that world inequality has recently (especially during the years of neoliberal 'globalization' since, say, 1980) been rising fast and has reached unprecedented levels. Yet at the same time, with few exceptions, the opinion of most academic economists who have carried out quantitative studies of the question is that the opposite has occurred and that recent decades have been ones of diminishing world inequality. Is this a difference based on misunderstanding, on different conceptual visions, or on differences about the facts and how to interpret them? This article seeks to clarify these questions by looking at the figures, their types and sources and then to see how much the differences are apparent or real.

Another kind of more general information has also helped to convey the impression that world inequality has grown and is growing: estimates of the income or product per head of individual countries of groups of countries. The three following graphs show the level of GDP per head, measured at purchasing power parity (the significance of which will be discussed later) for continents or parts of continents relative to the figure for the world: Figure 1, derived from the recent work of Angus Maddison, is for the years 1820 to 1998 (with an expansion of the scale of the graph after 1950); and Figure 2 (using World Bank statistics) shows more detail for the years 1980 to 2000. There have evidently been many phases in the continental patterns of equality and inequality; up to 1900 Western Europe's rise in relation to the world level was not nearly as fast as that of North America; Southern Europe and Latin America remained at the same relative level and the rest of the world deteriorated. From 1900 to 1950 Western Offshoots (USA, Canada, Australia and New Zealand) continued to surge ahead, Western and Southern Europe fell back, Latin America and Eastern Europe rose; after 1950 Southern and Western Europe and later Asia rose fast while Latin America and later more precipitately Eastern Europe fell back. North America relatively fell back as other countries recovered from the war but since the mid 1970s (despite much talk of a general economic crisis) it has resumed its relative rise, ending the century at a historical maximum.

What is constant is that for two centuries Africa's position relative to the world has worsened. The ratio between the income per head of the Western Offshoots (North America plus Australasia) in 1820 and of Africa is calculated at about 2.6 to 1; after 2 centuries of continuous fall it had by 1980 reached 12 to 1 and by 1998 almost 20 to 1 . It is not surprising that there is a common perception of growing inequality. Nor is it wrong since these figures are strongly suggestive of the growth of world inequality in general as well as equalities between particular continents or countries.

This paper is mainly concerned not with such particular inequalities but with the question of whether, by using available economic statistics, it is possible to obtain an overall assessment of the degree of world inequality and say definitively how it has changed. Some systematic comparison of recent estimates is needed as a guide to an increasingly studied subject which must produce great confusion in an uninitiated reader who sees some of the statements in the two lists in Box 1, most of them taken from academic studies or from international organization sources generally regarded as authoritative. 
The apparent inconsistency of these two lists has three causes: the use of different concepts of what equality and inequality are; the way in which those concepts should be measured; and inconsistencies in data obtained from different sources. In the hope of clearing the ground of all this undergrowth, this paper proposes to outline the problems of method, measurement and data in assessing the movement of global inequality. It then surveys and compares a considerable number of existing studies and adds its own additional calculations in the hope of clarifying the differences and of suggesting some new lines for research. It ends by commenting on the ideological and political meaning of the debate.

Figure 1a. Income levels relative to the world average 1820-1998

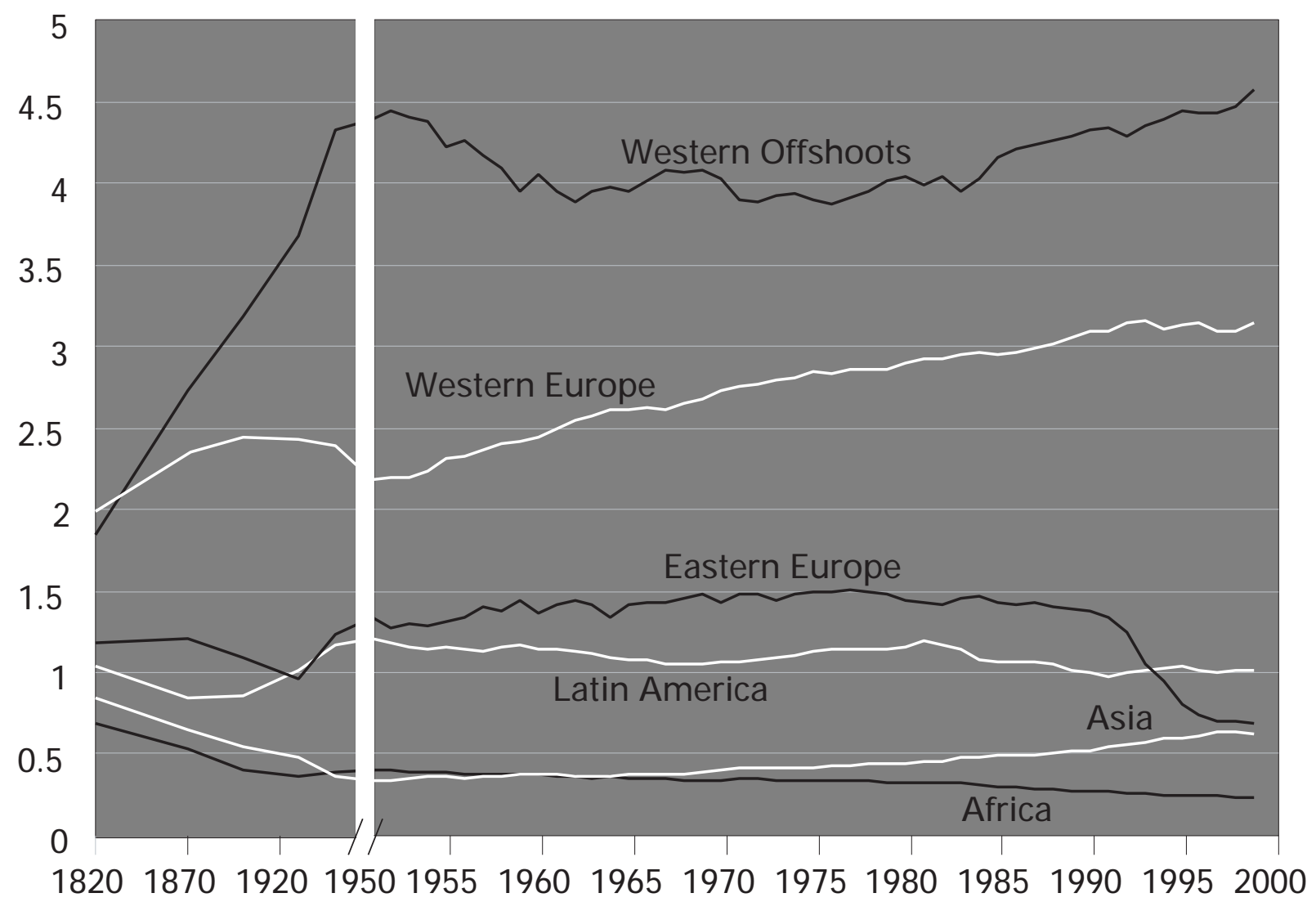

Source: Author's calculations based on Maddison 2001 
Figure $1 \mathrm{~b}$ : Income levels relative to the world, 1980-2000

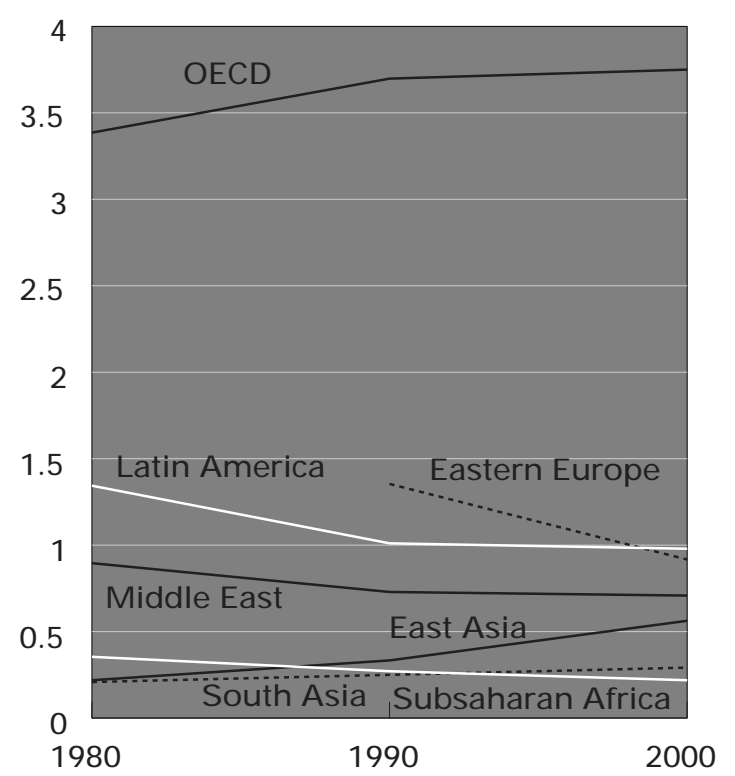

Source: Author's calculations based on World Bank, World Development Indicators 2002, online edition 


\section{Box 1: Convergence or divergence: some recent opinions}

"The evidence strongly suggests that global income inequality has risen in the last twenty years. The standards of measuring this change, and the reasons for it, are contested but the trend is clear."

Robert Wade ("Inequality of World Incomes: What Should be Done?")

"The dramatic advance of globalization and neoliberalism ... has been accompanied by an explosive growth in inequality ..."

Ignacio Ramonet (Le Monde Diplomatique May 1998)

“... poverty and inequality have grown alongside the expansion of globalization. In a world of disturbing contrasts, the gap between the rich and poor countries and between rich and poor people continues to widen."

Kevin Watkins (Background paper for UNDP, Human Development Report 1999)

"Gaps in income between the poorest and the richest countries have continued to widen. In 1960 the $20 \%$ of the world's people in the richest countries had 30 times the income of the poorest $20 \%$ in 1997, 74 times as much. This continues the trend of two centuries." (UNDP, Human Development Report 1999, Ch.1, p. 36)

"In 1960 per capita GDP in the richest 20 countries was 18 times that in the poorest 20 countries. By 1995 this gap had widened to 37 times, a phenomenon often referred to as divergence... Such figures indicate that income inequality between countries has increased sharply over the past 40 years." (World Bank, World Development Report 2000/2001, Ch. 3 p. 51)

"The gap between the rich and poor nations is now at its highest ever level". (Richard Jolly, Global Inequality, Wider Angle, December 1999)

$* * * * * * * *$

“...world wide divergence in per capita GDP increased steadily from the beginning of the century to the early 1980s. A turning point occurs, however, around 1980. The more rapid growth rates of India and, especially, China in more recent years have led to some modest convergence." (A. Boltho and G. Toniolo, "The Assessment: The Twentieth Century: Achievements, Failures, Lessons", Oxford Review of Economic Policy, Vol 15, No.4)

"Roughly speaking, the peak of world inequality was reached in the middle of the 20th Century after more than a century of continuous divergence. Since then, and in comparison with such a dramatic evolution, changes observed during the last 50 years look minor ones and the situation would seem to be stabilizing." (F.

Bourguignon and Christian Morrisson, "Inequality among world citizens: 1820 1990", draft February 2001).

"...we estimated nine measures of global income inequality. All of them deliver the same picture: inequality declined substantially during the last two decades."

(Xavier Sala i Martin, The World Distribution of Income (estimated from individual country distributions), NBER Working Paper 8933)

"When international inequality is appropriately measured on the basis of purchasing power parity (adjusting for different price levels) rather than official exchange rates, and countries are weighted according to the size of their populations, plausible measures of international inequality indicate that income convergence has taken place since the late 1960s." (Arne Melchior, Global Income Inequality: beliefs, facts and unresolved issues, World Economics, Vol 2 No 3 July September 2001)

"...the evidence suggests that the increases in world wide inequality in recent years are small relative to the much larger increases that occurred during the 19th century". (World Bank, World Development Report 2000/2001) 


\section{What to measure: integral measures versus ratios of groups}

Two common ways of looking at world distribution (or any distribution for that matter) are to compare the extremes of the distribution (the ratio of the incomes of the rich to the incomes of the poor), or to use all the data and produce an integral measure of distribution, of which the Gini coefficient is by far the most widely used. Both these methods can be used to calculate either distribution which takes into account only the differences between countries (referred to here as inter-country distribution) or distribution which also takes into account differences within countries (referred to here as global distribution). This gives us the four possible approaches to world distribution shown in Table 1.

Table 1: Different concepts of world distribution

\begin{tabular}{|c|c|c|}
\hline & Integral measure & Ratio of extremes \\
\hline Inter-country & A & C \\
\hline Global & B & D \\
\hline
\end{tabular}

Is an integral measure better than a ratio of extremes? The ratio of extremes has the advantage that it can be understood much more intuitively while integral measures, such as the Gini coefficient, are more abstract and require more explanation. On the other hand the ratio of extremes only compares two parts of the available data and so at best can give a limited view of the distribution. Measures of the ratio of extremes can in some cases use all the available data (for instance by measuring the ratio of the income of the top to that of the bottom half of the population, sometimes called the Robin Hood index); but even this gives no more than a relation of two summary figures. On the other hand the ratio of extremes may be a better approximation to the level of social justice than integral measures. This point can be illustrated with an example: suppose that we observe the following levels of income per head by quintiles of the same population in years 1 and 2 .

Table 2: A hypothetical example of two distributions

\begin{tabular}{|l|c|c|c|c|c|}
\hline & Quintile I & Quintile II & Quintile III & Quintile IV & Quintile V \\
\hline Distribution 1 & 1 & 1 & 1 & 1 & 15 \\
\hline Distribution 2 & 1 & 16 & 16 & 16 & 16 \\
\hline
\end{tabular}

Which of these two distributions is more egalitarian? In this example, which, as we shall see, is not too far removed from some aspects of world reality, the two types of measure give completely different answers. In Distribution 2 shows a higher ratio of extremes (the top divided by the bottom quintile) and so greater inequality than 
Distribution 2 (16 to 1 as opposed to 15 to 1 ). The Gini coefficient, however, shows a spectacular reduction in inequality, falling from 0.589 to 0.185 .

There could be a long debate about which of these distributions shows more social justice. But it is at least arguable that a society where four fifths of the people were rich and one fifth poor is morally worse than one where four fifths are poor and one fifth is rich. This is on the grounds that the exclusion of a small minority in conditions of general plenty is worse than great riches for a few amid general poverty, since only in the first case could everyone be made comfortable with only a small amount of redistribution. In other words, extreme poverty can be considered more unjust in a generally rich than in a generally poor society.

This point is not just a formality but, as will be seen later, is relevant to the interpretation of the conclusions about the course of income distribution during the last century. It suggests that it would be wise to look at both kinds of measures in order to judge the changes in equality and inequality.

\section{How to compare incomes: exchange rates versus purchasing power parity}

A very large amount of the disagreement and confusion about what has been happening to world income inequality has been due to the fact that two different ways of comparing the incomes of different countries are in common use - the exchange rate method and the purchasing power parity method. They both start from the same income figures, taken from the national accounts or from household surveys or other sources. These are, of course, in the first instance in national currencies. For countries to be compared, and world calculations made, they must be converted to a common currency. This has traditionally been done by converting them via the ruling exchange rate to dollars. The problem with this is that, as nearly everyone accepts, exchange rates very often fail to reflect equivalence of purchasing power. A person from one country going to another and changing currency will often find his or her purchasing power increased or reduced. The exchange rate-converted figures for income, therefore, produce false comparisons. The general solution proposed is the use of purchasing power parity, a calculation, based on an exhaustive exploration of prices in different countries, of what is the real equivalence of a quantity of one currency when converted to another. In practice, it appears that countries whose exchange rate underestimates purchasing power are mostly poor countries and those with the opposite characteristic are mostly rich countries. This means that when calculations are made using ppp the numerical measure of inequality between the richer and poorer countries tends to be lessened. In principle, however, this is a real comparison of material living standards which the figures converted with exchange rates are not. The ppp method is, therefore, overwhelmingly favoured by economists. It enables income levels between counties (over space) to be compared in the same way that in each country adjustment for inflation produces real figures which can be compared over time. This space and time comparability constitutes the great breakthrough of ppp figures which have recently become available in abundance. 
The difference in methods produces enormous differences in calculations about inequality, as shown in Table 3.

Table 3: Calculated world inequality in $\mathbf{2 0 0 0}$

\begin{tabular}{|l|r|r|}
\hline Measure & ppp & $\begin{array}{r}\text { exchange } \\
\text { rate }\end{array}$ \\
\hline 1. Inter-country Gini coefficient 2000 ppp (163 countries) & 0.543 & 0.753 \\
2. Inter-country $5 \% / 5 \%$ ratio 2000 & 47.95 & 175.31 \\
3. Inter-country $10 \% / 10 \%$ ratio 2000 & 31.37 & 126.08 \\
4. Inter-country 20\%/20\% ratio 2000 & 15.99 & 67.03 \\
5. Inter-country 50\%/50\% ratio 2000 & 5.38 & 20.09 \\
\hline
\end{tabular}

Sources: World Bank, World Development Indicators 2002 online version. The exchange rate conversion uses the World Bank's Atlas method (using exchange rates averaged over a year).

These figures are all based on the same 163 countries (the maximum for which the quoted source gives both exchange rate based and purchasing power parity based estimates of income). So the two columns show only the difference produced by the type of income conversion used. The exchange rate converted figures used are those described by the World Bank as the Atlas method, in which the exchange rate used is an average for the year rather than the rate on a particular date. Comparing the two columns it is obvious that the exchange rate method gives much higher measures of inequality than the ppp method, although of course the reality they are attempting to describe is identical. The Gini coefficient is nearly half as high again and the ratios of the extremes show indices of inequality around 4 times greater than the ppp method. In addition, as shown in Table 4, when observed over time the two methods give very different results. In general over the past two decades the exchange rate method shows the level of world inequalty rising and the ppp method shows it falling. Later some exceptions and nuances to this generalization will be discussed but for now the figures in Table 4 show a very simple calculation based this time on 113 countries (those which have data for both dates) to clarify the problem. Not only is the exchange rate based Gini higher in both years but it rises from 1980 to 2000 indicating greater inequality while the ppp based Gini falls indicating greater equality. This fundamental difference is the result only of the difference in the basis of conversion since the basic data are the same in both cases.

Exchange rate figures do not necessarily give higher values for the level and growth of inequality. The basic reason for the differences shown in Tables 3 and 4 is that exchange rates in poor countries have tended to be undervalued in foreign exchange markets in relation to their domestic purchasing power (a phenomenon well known to tourists). In addition during the years 1980 to 2000 the relative undervaluation in many poor countries increased and the relative overvaluation of the all important currency of the USA also tended to increase. In very recent times, however, the renewed fall in the international value of the dollar and a slower rate of devaluation in many poorer countries has done something to reverse the trends observed. 
Table 4. Changes in Gini coefficient 1980-2000, exchange rate and ppp methods of comparison

\begin{tabular}{|l|r|r|}
\hline & Exchange rate (Atlas) & ppp (World Bank) \\
\hline 1980 & 0.7053 & 0.6137 \\
\hline 2000 & 0.7449 & 0.5422 \\
\hline
\end{tabular}

Source: Author's calculations based on World Bank, World Economic Indicators 2002, online edition; the same 113 countries are common to all four calculations.

Since they give very different levels of inequality and opposite trends it is obviously of fundamental importance to decide which method is correct. It seems completely clear that in principal the correct measurement for comparing living standards (and so the real levels of international inequality) is given by the ppp method. This is based on the conversion of incomes using an index (a kind of shadow exchange rate) calculated on the basis of detailed comparison of the price levels of the same commodities between countries. In this way the effect of changes in exchange rates on the apparent distribution of world income is eliminated in a similar way to that in which comparisons between dates are made real by adjustment for price differences over time. So in principle the ppp figures allow a matrix in which the figure for the income per head of each country over time is comparable both vertically (over time) and horizontally (over space), in other words the figures are both temporally and spatially real. Since the measurement of inequality is concerned with real differences in living standards this is surely the correct procedure. Nearly all writers on the subject accept this; indeed it is the recent multiplication of ppp income estimates which has permitted the rise in the analysis of world income disparities. A few writers nonetheless claim that exchange rate conversions produce a more accurate picture of relative economic power which countries can only obtain by converting their undervalued currencies into high valued currencies (for example, to spend on renting an office in New York or Geneva from which to lobby international organizations). This argument may have some small merit in relation to the international power of countries but has none in relation to the measurement of inequality in the standard of living. Most use of exchange rate based calculations of world inequality, however, are not based on such arguments but on an desire to produce a particular result. This will be discussed further but in the meantime it should be made clear that from now on all calculations made and referred to in this paper use ppp methods. These methods, however, have their own problems.

\section{Different sources of ppp income data}

All ppp estimates of incomes come ultimately, though not directly, from the same source - the International Comparisons Program, a joint venture of the United Nations and the Center for International Comparisons at the University of Pennsylvania (for more details see http://www.worldbank.org/data/icp). The estimates are made by converting conventional national accounts figures in national currencies to international prices, established through price surveys (revised every three years) currently in 118 countries. The purpose of the exercise is to eliminate the price variations between countries for 
equivalent products and services and so make the value of these comparable between countries.

If in principle ppp converted figures are much better reflections of real differences in living standards, in practice there are three separate sources of ppp estimates which are by no means identical. One of these is from the World Bank data bank, World Development Indicators (WDI), the second from the latest version (number 6) of the Penn World Tables, produced by Heston, Summers and Aten and their colleagues (PWT6.1) and the third produced by Angus Maddison working under the auspices of the OECD (Maddison 2001).

The work of Maddison and of Heston and Summers and their associates, in producing a continuous series of figures for income per head (and other variables) since distant dates and in figures which are in principle comparable over both time and space is what has made possible a debate on the history of distribution between countries. Maddison's data begin in 1820 for some countries and have recently been updated to 1998 for most countries, while Heston and Summers' series for a growing number of countries covers the period from 1950 to 1998. The World Bank's ppp data begin in 1975.

While all three estimates use the price data produced by the World Comparisons Project, they adjust in various ways so that considerable differences emerge between the different estimates. As we shall see, the differences are great enough to imply different conclusions about the recent course of movement of world inequality.

Each person or group who has analysed the basic ppp data has added his or her own eccentricities. To take a single case which is bound to have major effects of international calculations, that of China: between 1980 and 1990 the real income per head of China, measured at ppp, increased by 36 percent according to the Penn World Tables version 5.6, 63 per cent according to the Penn World Tables version 6, by 85 per according to Maddison's 1995 study and by 70 per cent according to Maddison's 2001 revision; it is not possible to give a comparative figure for the World Development Indicators since it gives the data only in current prices. In the face of differences of that degree about the second largest economy in the world it is evident that any conclusions must be treated with extreme caution. Where possible, different estimates should be tested to see the degree of robustness of the conclusions to different versions of the income data. I have tried to do this in most of my later calculations.

Table 5 gives some details of the differences between estimates made by the three sources. For Maddison 2001 and PWT6.1 I have taken the 92 countries for which both versions have estimates, and almost the same group of countries for the World Development Indicators; to make them comparable the figures for all countries have been normalized as a proportion of the estimate for the USA (since the Maddison 2001 and PWT6.1 base years are different and WDI is in current prices). The comparisons between them appear in Table 5. This shows large enough variations between the three sources to feed doubts about the use of these figures. 
Table 5: Variability of estimates of GDP per head, 1998

$\begin{array}{lcr}\text { PWT6.1-Madd2001 } & 45.7 & 62-291 \\ \text { Madd2001-WDI2002 } & 34.4 & 36-326 \\ \text { PWT6.1-WDI2002 } & 48.9 & 70-202 \\ \text { Based on figures for } 1998 \text { in each case for about } 90 \text { countries; the countries } \\ \text { used in each comparison are the same for both measures compared }\end{array}$

Source: Author's calculations based on Maddison 2001 and Heston, Summers and Aten 2002 and World Bank 2002

The first column shows the percentage of the country income estimates of the second mentioned source which are within 10 percent (above or below) of the country estimates of the first mentioned source (so, for example, only 45 percent of the Maddison 2001 values are within 10 percent of the PWT values); the second column shows the range of the country estimates of the second mentioned source as a percentage of the first (so, for example, the Maddison 2001 values vary between 62 percent and 291 percent of the PWT values). These divergences seem very large indeed.

\section{Table 6: Comparing Gini coefficients produced by 3 income sources}

\begin{tabular}{|c|c|c|c|c|c|c|}
\hline & \multicolumn{2}{|l|}{ PWT6.1 } & \multicolumn{2}{|c|}{ Maddison 2001} & \multicolumn{2}{|l|}{ WDI 2002} \\
\hline & Gini & countries & Gini & countries & Gini & countries \\
\hline 1980 & 0.582 & 92 & 0.587 & 92 & 0.618 & 87 \\
\hline 1990 & 0.563 & 92 & 0.569 & 92 & 0.587 & 90 \\
\hline 1998 & 0.523 & 92 & 0.539 & 92 & 0.542 & 90 \\
\hline aximu & number o & countries & & & & \\
\hline 1950 & 0.523 & 53 & 0.551 & 198 & n.a. & n.a. \\
\hline 1973 & 0.591 & 115 & 0.574 & 217 & ${ }^{*} 0.612$ & *117 \\
\hline 1990 & 0.564 & 134 & 0.569 & 219 & 0.577 & 161 \\
\hline 1998 & 0.519 & 140 & 0.564 & 219 & 0.543 & 167 \\
\hline
\end{tabular}

Note: in the case of PWT6.1 and WDI 2002 the rising number of countries reflects the existence of data for an increasing number of countries. In the case of Maddison the data is for the same countries which change in number due to political changes (fusions and breakups)

Source: author's calculations based on Heston, Summers and Aten 2001, Maddison 2001 and World Bank 2002

The three sources produce estimates of the Gini coefficient which are rather closer than the differences in estimates of individual countries' GDP per head might suggest. This is partly because many of the biggest differences are for small and poor countries and because some of the differences cancel each other out. The upper half of Table 6 
compares the Gini coefficients given by the three sources using the same 92 countries for PWT6.1 and Maddison 2001 and nearly the same for the WDI. The differences in the Gini coefficients are surely small enough to be within any reasonable margins of error. All three show a falling Gini coefficient for the years 1980 to 2000 and the differences are not large; it is significant, as we shall see, that Maddison 2001 shows the lowest fall in the coefficient. When the calculation is made not for the same group of countries in each case but for the maximum for which they respectively provide estimates in the years 1950 to 1988 the differences are more striking. The result is shown in the lower half of the table. Both PWT6.1 and WDI still show a falling Gini coefficient (that is, falling inequality) but Maddison 2001 shows scarcely any fall at all. These calculations are done here merely to illustrate the differences in the data. Later we shall see that the difference is significant for conclusions about world inequality.

\section{Inter-country versus global distribution}

An obvious limitation of all the results mentioned in the previous section is that they only estimate distribution between countries as a whole (weighted, of course, by populations). They do not take into account the distribution of income within countries. This is like considering the whole world as a single economic unit and I refer to such a concept as global (as opposed to inter-country) distribution. It is evident that the objective of studies of world distribution must be to produce global and not inter-country estimates. We can hardly be confident in information about the world which assumes that 1,200 million Chinese citizens, or 280 millions US citizens receive respectively identical incomes. Gini coefficients are always larger when internal distribution is taken into account. Later in the paper a study will be described of 35 countries for which in the year 2000 the inter-country Gini coefficient was 0.515 while the global coefficient (the distribution data being quintile income levels in each country) was 0.619 . Since in national GDP per head figures the very rich and the very poor are averaged into groups poorer and richer than themselves respectively, the differences between inter-country and global ratios of extremes tends to be much larger than those of Gini coefficients. Since there is a widespread perception of a general tendency since 1980 towards greater inequality within nations then it is possible that, if this is taken into account in calculating world distribution, the results will be different. Theoretically changes in internal distribution (including more inequality) do not have to mean that global inequality is greater. Depending on how a country moves in the international income hierarchy, an increase in its internal inequality can be consistent with either an increase or a reduction in the global figure. Some of the studies to be reviewed later use statistical measures which are capable of decomposing changes in global inequality into between and within country effects. Nearly all of them concluding that in global distribution the between country effects have far greater weight.

The most fundamental problem in calculating global inequality is the inadequacy of national data about distribution. In particular very few long-term consistent series for distribution exist. So global, as opposed to inter-country inequality can only be observed over comparatively short periods, although Williamson has recently pioneered the use of historical wage data to reach conclusions about changes in inequality (Williamson 
and Lindert 2001).

Two methods have been used to try to assess the level and changes in global inequality in recent decades. One is to begin with the national income data used in the intercountry calculations and apply to it available estimates of distribution thus deriving the income per head of distributional groups (usually quintiles, occasionally deciles and rarely smaller percentiles). These figures (weighted by the appropriate population figures) are then pooled to calculate global inequality. The only attempt I have found to do this for a long historical period has been the study by Bourguignon and Morrison for the period 1910 to 1992. They use the Maddison 1995 income estimates weighted by data on distribution from a variety of sources, some of it based largely on plausible surmise. A recent study by Sala-i-Martin applies the same principle to a shorter time period (1970-1998), using for income the estimates in PWT6.1 and for distribution the Deininger-Squire database, to be discussed in the next section. Later I describe in detail my own study using the same principle in which I apply the Deininger-Squire distribution data to two sets of income data - the World Bank's World Development Indicators and Maddison 2001.

A recent study by Milanovic uses a second method. Instead of applying distribution data to independently obtained income data as in the three studies mentioned above he bases his whole analysis on household survey data which produce his distribution and income figures simultaneously. The consequences of this different method are discussed in section 8.

\section{Different sources of distribution data}

When it comes to comparisons over time and between countries the figures for GDP per head are certainty itself compared with those for the distribution of income. While the number of estimates for distribution is growing fast they are still much less systematically available than those for GDP per capita. For very few countries are long series available, and it is by no means certain that estimating methods in different countries or at different dates are consistent with each other. The study of international inequality has been given a big stimulus by the publication of the dataset produced by Klaus Deininger and Lyn Squire at the World Bank and the WIDER International Inequality Database (WIID) which takes the Deininger-Squire dataset as its basis. Deininger and Squire produce two sets of data for the years 1950 to about 1995: the total available and a reduced version of what they regard as the most reliable figures, called high quality or "accept". The criteria which they use for inclusion in this category are: income or expenditure data covering the whole national population from national household studies which use all income sources, including self-consumed production. The application of these criteria seems to give some coherence to the whole data set. But major reservations about its validity have been made by Atkinson and Brandolini (2001) as part of a critique of large international "secondary" data sets in general. Those authors point to significant inconsistencies between the Deininger and Squire highquality data and other, more intensively researched, sources of data on income distribution in the OECD countries and, due to the use of different definitions at different 
dates, they even conclude, using the case of the Netherlands as an example, that "it would be highly misleading to regard the DS [Deininger-Squire] "accept" estimates as a continuous series" (p. 780). If this is the case in a country where economic statistics are highly developed, the situation must be even worse in the majority of countries where they are not.

A perfectly understandable conclusion from the arguments of Atkinson and Brandolini, and many other criticisms of inconsistencies and unreliability in international income and distribution data, is that any attempt to calculate a figure for world distribution with distribution data for many countries over a considerable time-period must be completely unreliable and should perhaps be abandoned. Once data of this kind exists, however, whatever its limitations, the temptation to analyse it to see what it implies is too great to resist. The question of what is happening to distribution is too important for us to ignore even the inadequate evidence which we may have about it. And drawing provisional conclusions from the data we have, comparing them with other studies and observing inconsistencies could help the task of improving the future quality of the data. While Atkinson's and Brandolini's warnings are important, I have not let them stop me using our inadequate data to explore tentative conclusions. About the past there is virtually no hope that we shall ever have better data. So, as in the case of the income estimates, we should use it in a spirit of great caution.

\section{Inter-country studies compared}

I now turn from the problems of method in studying world inequality to a comparison of some of the studies which have been done, comparing the method, the data used, aspects of the treatment, the results obtained and the significance of the conclusions. This section discusses the results of inter-country studies and the next looks at global studies.

The number of countries included in each study is affected by the dates and the type of calculation. Inter-country studies require population and income per head figures for each country. Maddison provides such information since 1900 for 49 countries (for most of which the figures also go back to 1820). Unless extra estimates are made, centurylong studies are thus confined to these countries. For more recent dates more countries can be included, using any of the three sources of estimates discussed above in section 5 , namely the two versions of Maddison, various versions of PWT and the WDI. All three now provide annual estimates of ppp income covering countries which contain well over 90 percent of the world's population.

\section{7i. Long term studies}

The time periods covered by all the studies surveyed in this and the next section range from 98 years to five years. Both long and short term comparisons have alternative disadvantages relating to the data. In the case of long term comparisons the quality and completeness of the data is liable to change considerably over the period of the comparison. And in the case of short term comparisons a change in apparent 
distribution may easily be within the margins of error of the data. For this reasons longterm comparisons must be treated with general caution; and short-term changes should not be weighed very heavily.

There is no disagreement with the conclusion that during the twentieth century as a whole the world's distribution of income has become considerably more unequal. Maddison's 1995 data for 49 countries between 1900 and 1998 (as analysed by Boltho and Toniolo) shows an overall rise in the Gini coefficient from 0.393 to 0.496 . Maddison's data also show that this polarization between the richest and poorest countries has been a characteristic of the period since 1820. Using the same data and adding their own historical estimates of distribution changes Bourguignon and Morrison in their global study produce a pattern of change of the long term evolution of the global Gini coefficient which is broadly consistent with the Maddison 1995 inter-country distribution. And other quantitative and qualitative data supports the conclusion that current inequality is much greater than historical inequality (Williamson 1997, O'Rourke 2001). It seems that there is general agreement, based on the estimates available, that the world's countries became considerably more unequal between the Industrial Revolution and at least the end of the great post-Second World War boom in about 1973.

\section{7ii. Medium term studies}

While the long-term conclusion is not challenged, a large amount of disagreement, alluded to in section 2, has recently emerged on the question of what happened to world distribution during the last two decades. This rapidly developing debate was partly generated by the study in which Boltho and Toniolo calculated the long term Gini coefficient from Maddison's data. They showed that although inequality had grown during the twentieth century as a whole it had, using the same data, distinctly fallen since 1980, the Gini falling from 0.544 to 0.496 in 1998 (see Table 7, row 2).

How secure is the conclusion reached by Boltho and Toniolo? The first possible problem with it is that, since their aim was to view changes in distribution over the whole century, the calculations only contain the 49 countries which have the appropriate figures for that period. What happens if more countries are included? I repeated the same calculation based on World Bank GDP per head figures (ppp) for the 121 countries for which figures exist for the controversial shorter period from 19801998. The inclusion of 72 more countries (many of them relatively poor countries) actually reinforces the earlier conclusion: while the Gini has a higher value in 1980 it nonetheless falls relatively slightly more up to 1998 (from 0.610 to 0.538 , line 4 ). There are two reservations to this conclusion: first that the effect of China is very great. If China is excluded from the calculation then the Gini actually rises a little from 0.555 to 0.561 (line 5). And second, there are still many countries missing from the study for lack of comparative ppp income per head figures. Since a number of these are very poor countries which are known to have been become poorer in this period, then a complete count might reduce the fall in the Gini.

Substituting the Penn World Tables data for the Maddison 1995 does not change the 
direction of the result. Summers and Heston find a slightly smaller fall in the Gini between 1980 and 1990 (compare 1 and 2); their data (PWT5.6) at the time of writing did not yet allow the calculation of the Gini beyond 1992. Firebaugh and Melchior and Telle, both using PWT5.6 (in the latter case updated by the World Bank), both produce fairly similar results (lines 3 and 6). My own calculation based on PWT6.1 also shows a comparable fall in the Gini coefficient (line 7).

What does make a real difference to the inter-country estimates is using Maddison's more recent figures (Maddison 2001) instead of the earlier ones, used by Boltho and Toniolo. The differences in the new series are: more countries are included (which means especially including very poor countries previously omitted); the estimates for many countries have been changed somewhat; and, most important, the estimates for three countries - Japan, India and most importantly China - have been thoroughly redone (see Maddison 1995, 1997 and 2001). Maddison's new data shows the Gini coefficient falling from 1973 to 1980 , rising again from 1980 to 1990 , and then falling very slightly up to 1998 . Once again the exclusion of China produces a noticeable increase in the Gini for the rest of the world (lines 8 and 9).

Table 7: Inter-country Gini coefficients, 1950-1998 (also see Figure 2a)

\begin{tabular}{|l|r|r|r|r|r|}
\hline Author and income data source & \multicolumn{1}{|c|}{1950} & \multicolumn{1}{|c|}{1973} & \multicolumn{1}{c|}{1980} & \multicolumn{1}{c|}{1990} & \multicolumn{1}{c|}{1998} \\
\hline 1. Summers \& Heston (PWT 5.6) & & & 0.552 & 0.547 & n.a. \\
\hline 2. Boltho \& Toniolo (Maddison 95) & & & 0.544 & 0.526 & 0.496 \\
\hline 3. Firebaugh (PWT 5.6) & & & 0.550 & ${ }^{*} 0.543$ & n.a. \\
\hline 4. Author's calculation (WDI 2002) & & & 0.610 & 0.584 & 0.538 \\
\hline 5. as above omitting China & & & 0.555 & 0.562 & 0.561 \\
\hline 6. Melchior \& Telle** (PWT 5.6 updated) & 0.523 & 0.591 & 0.57 & 0.56 & 0.52 \\
\hline 7. Author's calculation (PWT 6) & 0.550 & 0.573 & 0.555 & 0.564 & 0.519 \\
\hline 8. Author's calculation (Maddison 01) & & & 0.532 & 0.569 & 0.564 \\
\hline 9. as above omitting China & & & & 0.582 \\
\hline
\end{tabular}

$*=1989$

** = figures approximate (read-off from graph)

Sources: see bibliography 
Figure 2a: Inter-country Gini coefficients, 1950-1998

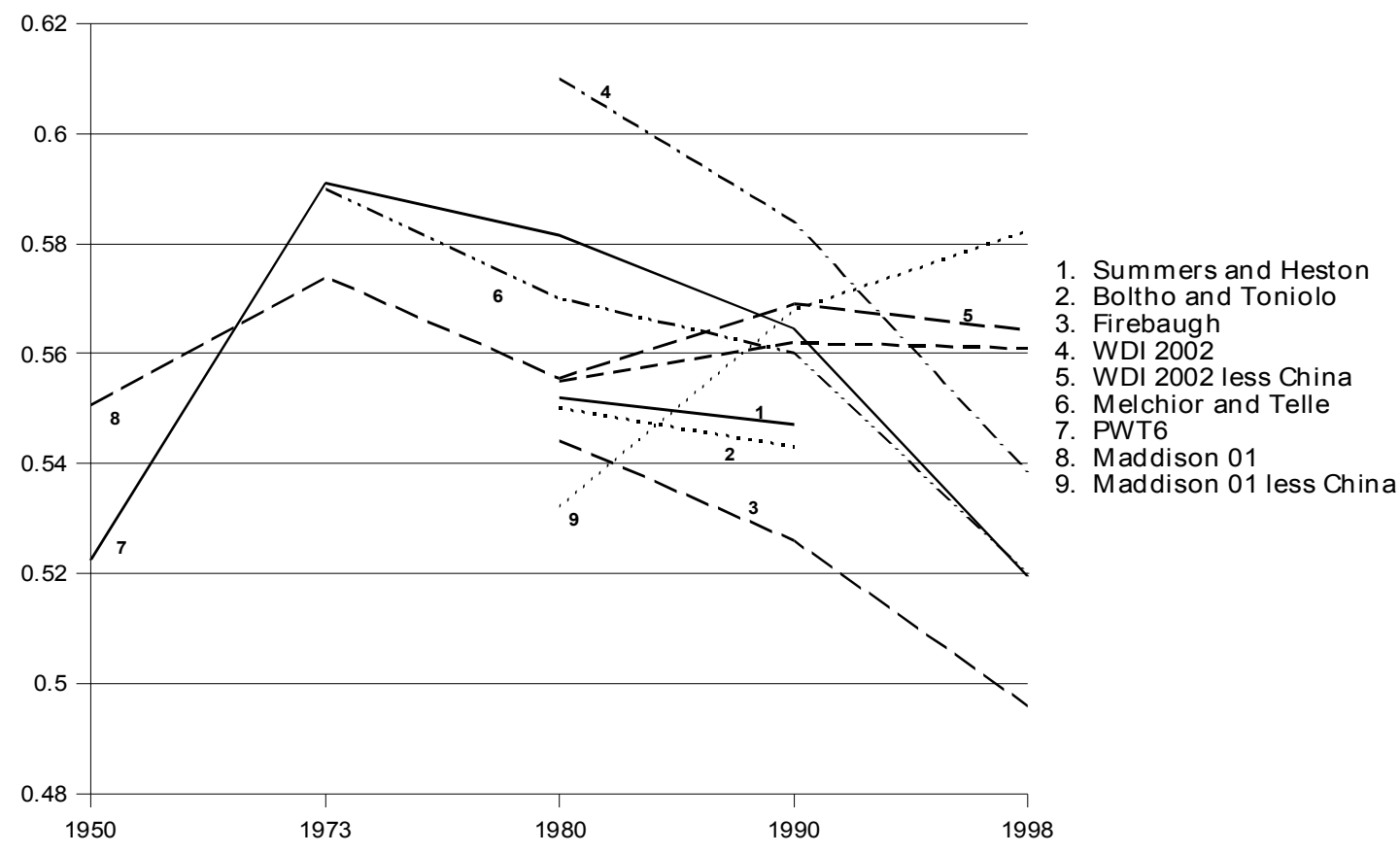

Figure 2b: Global Gini coefficients, 1980-2000

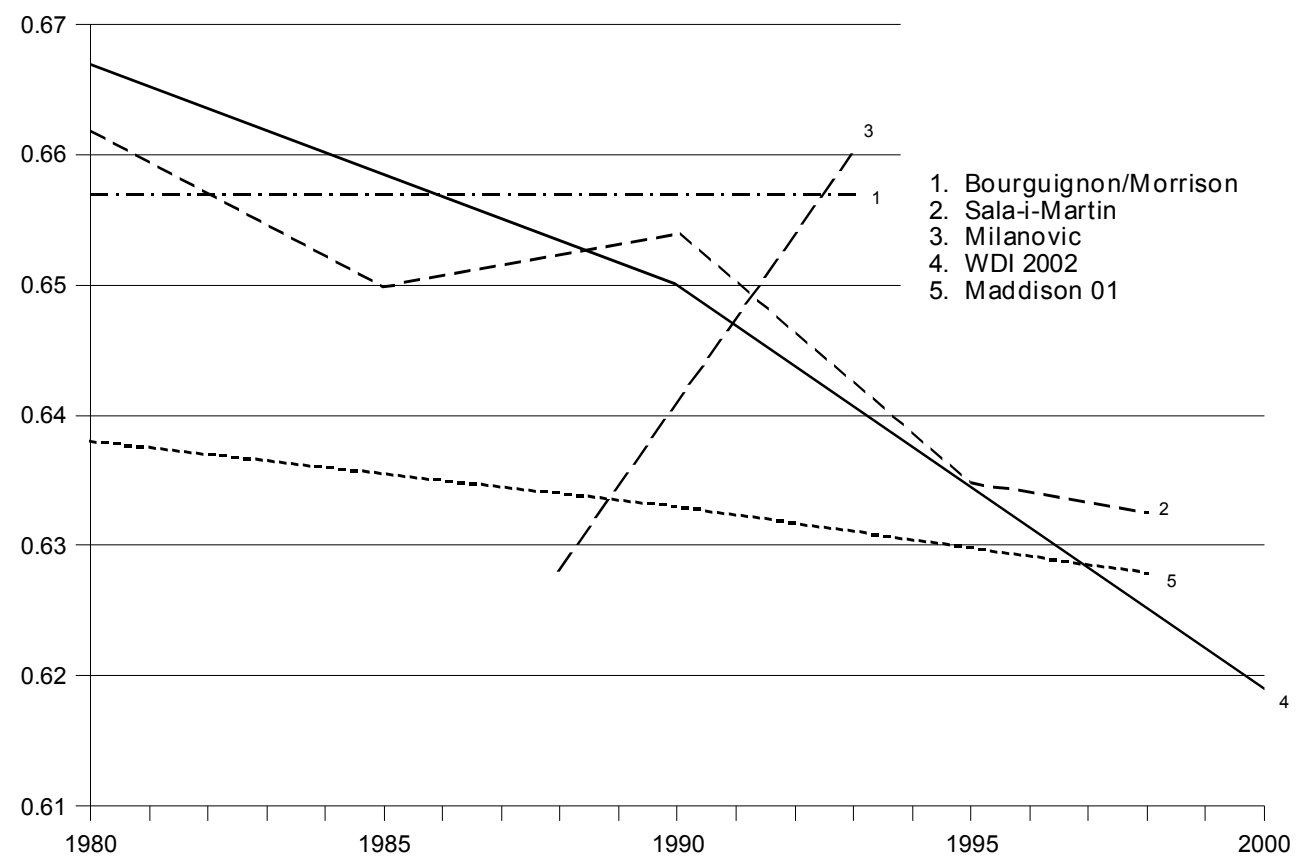


The conclusion from comparing these calculations (all using ppp figures, but with differing numbers of countries) is that the Maddison 1995 income estimates, the Penn World Tables and the World Bank WDI figures give consistent results, all showing either a slightly or moderately declining Gini coefficient, in other words less inter-country inequality, during the two decades following 1980. The exception is the revised Maddison 2001 income estimates. These produce a slightly fluctuating Gini coefficient. The key changes in Maddison's data have been revisions of the figures for China and the fact that he has ventured to include indirect estimates for more countries than appear in the World Bank figures. The inclusion of two kinds of countries for which the World Bank does not estimate have the effect of changing the calculated trend towards less inequality: these are very rich countries (mostly oil producing) which experienced major falls in income per head during this period and a number of poor countries which experienced disastrous social situations (often civil wars) which led to declines in already very low income levels. While most of these calculations include a large majority of the world's population, the omitted minority cannot be assumed to follow roughly the same pattern. The countries included in fact may make a significant difference to the results.

Evidently no calculation of the world's income distribution can be performed without the inclusion of its most populous country, China. There are, however, two reasons why doing the calculations omitting China (as has been done in the above table for the World Bank and the Maddison 2001 figures) may be of some interest. The first is that since China has a disproportionate influence on the world figures which it is interesting to abstract from and the second is that there is considerable controversy about the correctness of different series for China's GDP over the years since the economic reform. The result suggests that the movement of Chinese national income, whatever the estimate, has had the effect of reducing inter-country inequality, as indicated by the Gini coefficient. The same point is discussed by Melchior (2001) and Schultz (1998).

I have also calculated various ratios of extremes using WDI (ppp) figures and Maddison's 2001 study several ratios of extremes. The results are shown in Table 8. The 50/50 ratio according to Maddison's figures and the 20/20 ratio according to both these estimates became less unequal during the whole period. But the 10/10 ratio behaved very differently. In the case of the World Bank figures it declined in the first decade but then becomes more unequal again in the second, leaving it at about the same level as it started. But according to Maddison's income estimates the difference was much more significant: the 10/10 ratio showed a strong increase in inequality at the extremes. 
Table 8: Inter-country ratios of extremes $1980-1998$

\begin{tabular}{|l|r|r|r|}
\hline & 1980 & 1990 & 1998 \\
\hline Richest/poorest 50\% WDI & 10.91 & 7.37 & 5.27 \\
\hline Richest/poorest 20\% WDI & 26.68 & 15.94 & 14.81 \\
\hline Richest/poorest 10\% WDI & 27.94 & 23.54 & 25.75 \\
\hline Richest/poorest 5\% WDI & 29.01 & 31.73 & 39.91 \\
\hline & & & \\
\hline Richest/poorest 50\% Maddison 2001 & 8.35 & 6.55 & 5.49 \\
\hline Richest/poorest 20\% Maddison 2001 & 16.82 & 28.19 & 18.58 \\
\hline Richest/poorest 10\% Maddison 2001 & 23.09 & 34.62 & 40.01 \\
\hline Richest/poorest 5\% Maddison 2001 & 30.03 & 45.40 & 61.14 \\
\hline
\end{tabular}

Source: author's calculations from World Bank 2002 and Maddison 2001

Figure 3: Ratios of extremes, $\mathbf{1 9 9 0 - 2 0 0 0}$

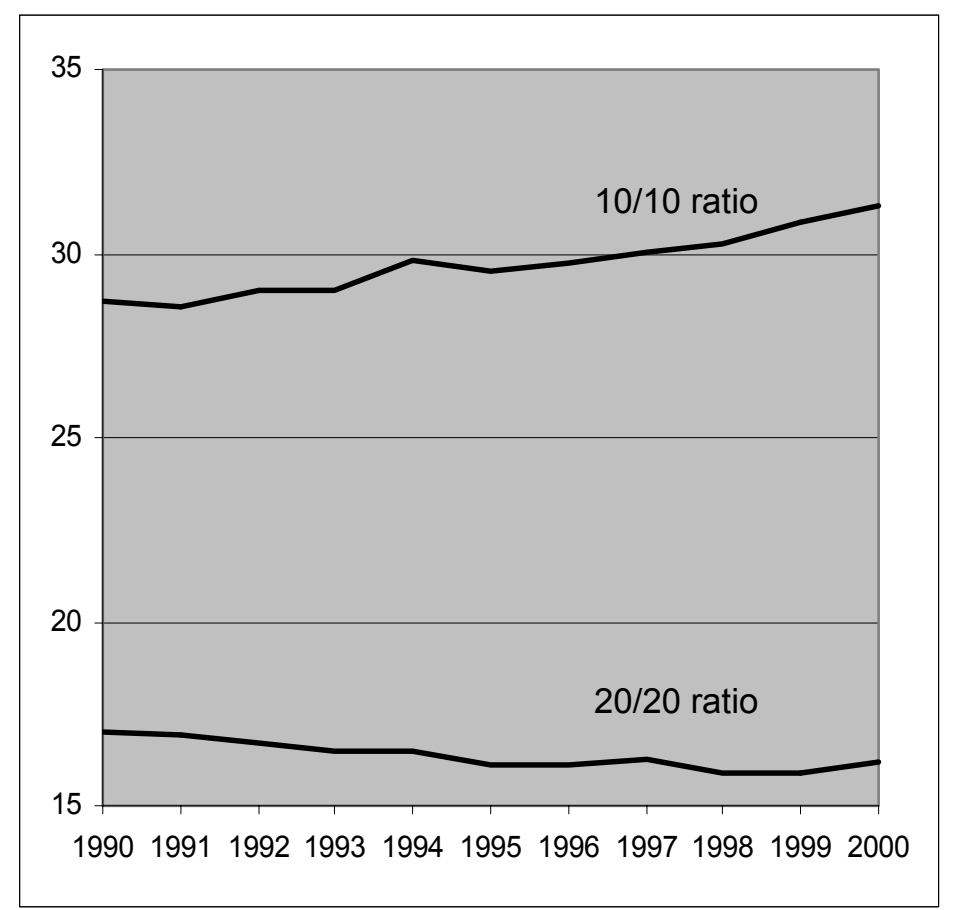

Source: World Bank, World Development Indicators 2002, online version

A similar result (using Penn World Tables figures updated by the World Bank) was obtained by Melchior (2000). And Figure 3, using annual calculations based on WDI, shows the divergence in the behaviour of the 20/20 ratio which slowly declines while the $10 / 10$ ratio appreciably falls during the 1990 s then very slowly begins to rise again. Looking at all of these figures together, therefore, begins to suggest that to say that inter-country inequality in the last two decades of the $20^{\text {th }}$ century either fell of was on a 'plateau' (Firebaugh 1999) or 'was roughly stable' (Bourguinon and Morrison 2001) is too simple. As well as being affected by the number of countries included and by the source of the income data, the overall conclusion about inequality depends on the statistic which is used to measure it. The contrast between the integral measure and the ratio of extremes suggests anything but stability or constancy. It looks more as if there 
were strong equalising forces in the middle sections of the distribution (which influence the Gini coefficient) combined with equally strong disequalizing ones at the extremes. There will be more evidence of this when we move to look at global, as opposed to inter-country, inequality.

\section{Global studies compared}

Of the four global studies, three apply distribution estimates to independently obtained income estimates and the fourth (that of Milanovic) derives both distribution and income at the same time from World Bank household surveys. While some of the studies use various statistics to test changes in inequality, I have restricted comparisons to the Gini coefficient. Partly this is to save space and simplify the argument. But also it is because none of the alternative measures used by other authors substantially changes the conclusions of any of their studies, although it sometimes allows them to be more sophisticated.

Bourguignon and Morrison's estimates based on Maddison's 1995 income figures and various sources for distribution have already been mentioned. For the period after 1980 they provide only two observations, thirteen years apart. They are identical and lead the authors to argue that overall inequality has been stable in the recent period. Sala-iMartin uses PWT6.1 income figures and the Deininger-Squire database for distribution. He produces annual figures by deriving trend lines for the distribution data. If there is only one estimate of distribution then he applies it through the whole period. He concludes that from 1980 there has been a significant downward reduction in inequality, the Gini coefficient falling from 0.662 to 0.633 between 1980 and 1998 .

My own calculations, which are described in detail in the following section of the paper, were done in a way similar in principle to Sala-i-Martin's, though they are statistically much less intricate. They involve applying distribution estimates from the DeiningerSquire high quality dataset to two different income estimates: the World Bank WDI data and Maddison's 2001 data. Each of these two calculations was done with two sets of countries: a pure set of 35 countries in which a distribution estimate existed for all three years compared (or a year fairly close; see Appendix) and a second much larger hybrid set of countries some with very incomplete, sometimes non-existent, distribution figures. The exact methods are set out in the next section. 
Table 9: Values of Gini coefficients in global studies (also see Figure 2b)

\begin{tabular}{|l|r|r|r|r|r|r|r|r|r|c|}
\hline Authors (income, distribution) & 1970 & 1975 & 1980 & 1985 & 1988 & 1990 & 1993 & 1995 & 1998 & 2000 \\
\hline $\begin{array}{l}\text { 1. Bourguignon/Morrison } \\
\text { (Maddison 95, various) }\end{array}$ & & & 0.657 & & & & 0.657 & & & \\
\hline 2. Sala-i-Martin (PWT 6, D/S) & 0.657 & 0.661 & 0.662 & 0.650 & & 0.654 & & 0.635 & 0.633 & \\
\hline 3. Milanovic (Household surveys) & & & & & 0.628 & & 0.66 & & & \\
\hline 4. Sutcliffe pure (WDI 2002, D/S) & & & 0.697 & & & 0.658 & & & & 0.619 \\
\hline 5. Sutcliffe pure (Maddison 01, D/S) & & & 0.661 & & & 0.636 & & & 0.617 & \\
\hline 6. Sutcliffe hybrid (WDI 2002, D/S) & & & 0.667 & & & 0.650 & & & & 0.627 \\
\hline $\begin{array}{l}\text { 7. Sutcliffe hybrid (Maddison 01, } \\
\text { D/S) }\end{array}$ & & 0.638 & & & 0.633 & & & 0.628 & \\
\hline
\end{tabular}

Sources: see bibliography and section 9 of this paper. D/S = Deininger/Squire

As in the case of the inter-country studies all the estimates based on PWT6.1 and WDI (Table 9, rows 2,4 and 6), income data show an appreciable fall in inequality between 1980 and 1998/2000. The Bourguignon and Morrison estimate (1) based on Maddison 95 shows no change. My own (5,7), based on Maddison 01, shows an appreciable fall in the case of the pure study but very little change when a lot more countries are included. There seem to be two reasons for these differences: the number of countries included and the actual estimates. As mentioned in relation to the inter-country studies, Maddison in producing the latest version of his income study made major changes to his earlier estimates for a number of important countries, especially India and China, and these materially affect the outcome. He also took particular pains to include estimates (often not direct ones) of all countries and territories, including very small countries and countries for which the World Bank for example does not give estimates because of the virtual breakdown of government statistical services due to states of war and other causes. This means that Maddison includes more of the countries which have fared worst in recent decades, as well as a few very rich (oil producing and tax haven) countries which are also left out of other datasets. This is not to say that the estimates for these countries are necessarily very accurate but their inclusion makes the dataset particularly satisfactory for capturing a more inclusive image of global distribution. The result is that Maddison's data shows the global Gini coefficient falling only very slightly from 0.638 to 0.628 during the years 1980 to 1998 and, as already seen in the previous section, shows inter-country inequality virtually static. The combined effect of all these studies is to erode somewhat, but by no means entirely, the earlier impression of a sharp fall in inequality during this period.

The other global study, by Milanovic (3), produces a very different result, a rise in the Gini coefficient over a period of 5 years. His method is to begin not with aggregate national income estimates but with detailed household income or consumption survey data. Distribution and income data are thereby obtained together. It is, as he says, a much more natural way to conduct a study of global distribution than the two stage methods used by others. Such data has been collected for a number of years by the World Bank in their household surveys and Branko Milanovic has used these to calculate what he calls the first 'true' measure of global inequality (Milanovic 2002). His study is remarkable not only for its pioneering methodology but for the fact that, unlike most of the other studies so far reviewed it concludes that the global Gini coefficient 
(and other measures of inequality) has been rising fast in exactly the period during which other writers have concluded that it has been falling or steady. Another study by Nikhanov and Ward (2001), using the same household distribution data as Milanovic reaches an almost identical conclusion.

Interesting and innovative as it is, Milanovic's study has a number of limitations. The first is that it covers a very brief time span (1988 and 1993) which makes it impossible to draw from it a conclusion even about the two decades from 1980. The dates have been chosen because they were benchmark years for international price level comparisons (used in the production of ppp income and consumption data). But the dates of the household surveys do not always correspond to these years. Sometimes they related to nearby years which means that for a study based on two years which are only five years apart the range of years used in the surveys can overlap. The figures for 1988 are based on surveys made between 1980 and 1991 and those for 1993 on surveys made between 1990 and 1998. This limitation can be partly answered by saying that, assuming that changes in national distributions have generally moved in one direction, the observed rise in the global Gini coefficient suggests a general tendency towards rising global inequality between the 1980s and 1990s. But this problem nonetheless means that, despite its interesting conclusion, the study does not provide a definitive answer to the question of what happened to global distribution during the last two decades.

Milanovic decomposes the influences on overall global inequality into inter-country and intra-country components. He finds, like almost all others who have used such a technique, that the vast majority of global inequality is accounted for by differences between and not within countries. But his conclusion that growing inter-country differences are the main cause of the rise of the Gini coefficient over the five years of his study, seems in this case a rather eccentric one since he emphases the special contribution of the growth in rural/urban inequality in both China and India but he treats the rural and urban sectors in both cases as two separate "countries".

The studies which use the two stage methodology (starting with national income or product per head and then using quintile distribution data to produce income per head or quintile groups) give fairly consistent results while the one-stage method used by Milanovic (using household surveys directly to calculate income and distribution) gives a contrasting result. It is possible that this difference may be explained by the difference in method. Milanovic discusses why the two methods might be expected to give different results. But what he does not explain is why for 1988 his method produces a Gini coefficient which is (implicitly) slightly lower than any of those produced by the two stage method while for 1993 it produces one which is higher. It is not clear why the factors which can cause a two stage method to produce a different result from the one stage method should have changed over this five-year period so as to produce this reversal.

The final problem with Milanovic's study is that the comparability and reliability of household surveys may be no better than the comparability and reliability of the other statistics used in all the studies quoted. And, unlike the case of two-stage studies which 
use ppp estimates of product or income per head, there is in the case of the World Bank household studies only one source. This is not meant as a reservation about Milanovic's study in particular since in the end all studies of global equality depend on data of questionable reliability and many of them end up by using estimates of intra-country inequalities which are at least in part derived from the same World Bank household surveys used by Milanovic. But the difference between conclusions reached by his method and those produced by other methods (even where the underlying data are partly the same) does underline the importance of further work on comparing and improving data on income and distribution.

I am not, however, suggesting that no work is valid until the data improves. Rather that the problems of data mean that differing results arise due to differences in both data and method and that these cannot be considered definitive conclusions but rather hypotheses for which further support needs to be sought.

\section{Two additional calculations, $1980-2000$}

I have carried out two additional calculations for the three years 1980, 1990 and $1998 / 2000$, some of the results of which were already set out in the previous section but which are here described in detail. These are sufficiently different in method, data selected and results to make it worth describing them and comparing them to the other calculations mentioned above. I have calculated global values for both ratios of extremes and Gini coefficients, and the most interesting conclusion is the different pictures which emerge from comparing these measures. The income data used was taken both from the World Bank's WDI and from Maddison 01 and so allow a direct comparison of the differences resulting from using different data sources. Quintile distribution figures are from the Deininger-Squire distribution dataset supplemented for more recent years by the table on distribution which appears in World Development Indicators 2002 (book).

The two calculations use these same sources but treat them differently. The first (which I call the pure study) includes only those countries which have values for GDP (ppp) per head and estimates of inter-quintile distribution in each of the three years; no extra data has been extrapolated. The ideal country for the sample was one with figures for quintile shares in 1980, 1990 and 1998 (the most recent year possible). This strong stipulation means, of course, that the number of countries for which all this data is available in the cited sources is very limited; only 5 countries fulfilled these criteria. So countries were included if they had observations for inter-quintile distribution in years close to the three benchmark years. I had to be quite generous in interpreting this rule (as can be seen in the appendix note) in order to include 35 countries which accounted for $70 \%$ of the world population in 1980 and 1990 and $69 \%$ in 2000 and for a share of world GDP which rises from 61 percent in 1980 to 67 percent in 2000. The means that collectively the 35 countries have a lower than world average GDP per head but that they have improved relative to the world average during the years studied.

The second calculation (which I call the hybrid study) is based on the same data 
sources but extrapolates values where they do not exist in order to maximise the number of countries which included. The two changes made were:

a. where GDP per head figures were lacking for one or more of the years in the WDI dataset they were interpolated using one of two methods. In some cases the country was assumed to have the same relationship to the average for its continent as the nearest year in which a GDP per head estimate is available, except in specific cases where the same ratio was assumed to be maintained between the country lacking data and some other individual country (Mongolia with the Russian Federation; and Oman, Qatar and Kuwait with Saudi Arabia).

b. the distribution data was extrapolated by assuming that, when not available for a particular year, inter-quintile distribution remained the same as in the previous available year. Where no distribution data at all are available each quintile of the population is allocated one fifth of the income (i.e. total equality is assumed). Hence no assumptions have been made about what distribution might be or about how it might have moved. Missing estimates are all supplied by applying these simple rules and not by efforts to divine what happened.

These procedures allow the number of countries in the sample to be increased from 35 to 163 containing about 96 percent of world population. Of the extra 128 countries 4 (Mongolia, Oman, Qatar and Kuwait) are added due to the provision of an income estimate and the other 124 due to the addition of figures for inter-quintile distribution. A few countries had to be left out altogether since no comparable data exists at all on either ppp income or on distribution; these were Barbados, all the countries of former Yugoslavia, Cuba, Cambodia, Laos, Rwanda, Djibouti and Liberia.

Table 10: Results of the 'pure' study

Using WDI 2002 figures

\begin{tabular}{|l|r|r|r|}
\hline & \multicolumn{1}{|c|}{1980} & \multicolumn{1}{|c|}{1990} & \multicolumn{1}{|c|}{2000} \\
\hline Global Gini coefficient & 0.6977 & 0.6582 & 0.6192 \\
\hline Richest/poorest $50 \%$ & 12.6 & 9.5 & 8.0 \\
\hline Richest/poorest $20 \%$ & 42.2 & 30.4 & 24.5 \\
\hline Richest/poorest $10 \%$ & 74.6 & 69.9 & 47.7 \\
\hline
\end{tabular}

Using Maddison 2001 GDP figures

\begin{tabular}{|l|r|r|r|}
\hline & \multicolumn{1}{|c|}{1980} & \multicolumn{1}{|c|}{1990} & \multicolumn{1}{|c|}{1998} \\
\hline Global Gini coefficient & 0.6607 & 0.6359 & 0.6173 \\
\hline Richest/poorest $50 \%$ & 9.9 & 8.37 & 7.9 \\
\hline Richest/poorest $20 \%$ & 40.0 & 25.8 & 25.2 \\
\hline Richest/poorest $10 \%$ & 54.4 & 51.1 & 48.7 \\
\hline
\end{tabular}

Source: author's calculations based on World Bank 2002a and 2002b and Maddison 2001 
In the pure study (Table 10) the percentage fall in the global Gini coefficient for the global figure in the case of both income sources is in fact proportionately greater than the fall for the inter-country figure in the Boltho and Toniolo calculation using Maddison 95. For this sample of countries the inter-country Gini falls by much more that the Boltho and Toniolo figure. But in 1998 the global Gini, according to this calculation, is still higher than for any single country in the world with the exception of Sierra Leone (World Bank 2002). Once again Maddison 01 figures produce a smaller decline in inequality than the WDI 2002 figures. The almost total exclusion due to lack of data of SubSaharan African countries from this pure study must make a significant difference to the level and trend of the Ginis.

\section{Table 11: Results of the hybrid study}

Using WDI 2002 figures

\begin{tabular}{|l|r|r|r|}
\hline & 1980 & \multicolumn{1}{|c|}{1990} & \multicolumn{1}{c|}{2000} \\
\hline Gini coefficient & 0.6667 & 0.6504 & 0.6272 \\
\hline Richest/poorest 50\% & 13.62 & 10.21 & 8.83 \\
\hline Richest/poorest 20\% & 45.73 & 33.85 & 29.49 \\
\hline Richest/poorest 10\% & 78.86 & 64.21 & 57.41 \\
\hline Richest/poorest 5\% & 120.75 & 101.02 & 116.41 \\
\hline Richest/poorest 1\% & 216.17 & 275.73 & 414.57 \\
\hline
\end{tabular}

Using Maddison 2001 figures

\begin{tabular}{|l|r|r|r|}
\hline & \multicolumn{1}{|c|}{1980} & \multicolumn{1}{|c|}{1990} & \multicolumn{1}{|c|}{1998} \\
\hline Gini coefficient & 0.6385 & 0.6331 & 0.6285 \\
\hline Richest/poorest 50\% & 10.4 & 9.1 & 8.9 \\
\hline Richest/poorest 20\% & 33.0 & 30.5 & 23.1 \\
\hline Richest/poorest 10\% & 58.2 & 54.9 & 61.1 \\
\hline Richest/poorest 5\% & 139.4 & 98.6 & 123.1 \\
\hline Richest/poorest 1\% & 214.3 & 290.6 & 359.6 \\
\hline
\end{tabular}

Source: see Table 10

The results point to a growing gap between global and inter-country Ginis, suggesting that an increasing share of inequality between the inhabitants of the world is caused by internal rather than inter-country inequalities. A similar conclusion is reached by Bourguignon and Morrison and several other writers.

The hybrid study (Table 11) in effect adds data on inter-national distribution for 128 countries to the global data for 35 countries in the pure study. Perhaps surprisingly (since many African countries are now included) the overall Gini coefficient, for both income sources, is slightly lower in 1980 than that of the pure study. But, although it still registers a decline during the 18 years, the fall is very much less than in the pure study or in the inter-country Gini calculated using Maddison's 1995 data. Maddison 01 
produces a falling Gini coefficient but the fall is much smaller than that shown by the WDI data. More surprisingly in the case of the WDI figures there is a rather considerable decline in the $20 / 20$ and $10 / 10$ ratios. The latter is particularly surprising given that, as observed above, there is some evidence from other sources of an increase in inequality according to this statistic during the 1990s. But, if even smaller extremes are compared, the result does change and rather dramatically. The $5 / 5$ ratio falls during the 1980 s and then rises during the 1990s. Using the Maddison 01 figures this occurs for both the $10 / 10$ ratio as well. And in the case of both data sources there is an enormous increase in the ratio of the income of the richest to that of the poorest 1 per cent of the world's population, in other words about 60 million people at each end of the distribution. This ratio has very nearly doubled over the two decades studied.

From all the above global data, as in the case of the inter-country calculations, what seems to emerge is that within a decline or stabilization of inequality in one sense there is a growth of inequality in other senses. First, a small group at the top of the distribution has been separating itself off from the rest of the world distribution, and another group at the bottom have been suffering increasingly extreme privation, producing the ratios of extremes we have just seen. The largest component of the top group is the top quintile of the United States population. I suspect that the tendency would be even more marked if the internal quantiles were more detailed than the simple quintiles used in this study. Here, then, is evidence from another source of an extraordinary rise in income accruing to characters such as the CEOs of big companies, the "ultra high wealth individuals" and others whom we met in the first section of this paper and whose wealth, as well as their crimes and misdemeanours, came during 2002 to occupy a growing proportion of media and even government attention. In a second sense, too, inequalities between particular countries, continents or country groups are growing even when overall measures of world inequality show stability or decrease. A number of these cases will be looked at in the next section. Thirdly, even if there has been a recent decline in measured overall global and inter-country inequality, this cannot be interpreted as a sustainable trend. Sala-i-Martin is one of those who insists on the recent existence of declining inequality; nonetheless he adds the extremely important rider that, if the demographic and economic growth trends between and within countries which have existed for the last 20 years continue with no change, then they will before long lead to a renewal of the long-term increase in world inequality which characterized most of the twentieth century.

\section{More disaggregated measures}

Measures of world inequality are the net outcome of rises and falls of relative income for thousands of different groups of the world's inhabitants; we can perhaps, therefore, conclude more about the way in which inequality has changed by looking at more disaggregated measures. Although the number of countries for which internal distribution data are available over time is limited we can take countries in different parts of the world and see how they fared in relation to each other. That is done in Table12 which shows the ratio of the top 10 percent of the population of the United States to the bottom 10 percent of the population in four large countries, Brazil, China, India and 
Nigeria in 1980 and 1990 and 2000.

Table 12: Ratio of income per head of the richest US quintile relative to the poorest quintile in four poorer countries (income calculated in ppp dollars)

\begin{tabular}{|l|r|r|r|r|}
\hline $\begin{array}{c}\text { Country } \\
\text { Year }\end{array}$ & \multicolumn{1}{|c|}{ Brazil } & \multicolumn{1}{c|}{ China } & \multicolumn{1}{c|}{ India } & \multicolumn{1}{c|}{ Nigeria } \\
\hline 1980 & 46 & 157 & 96 & 152 \\
\hline 1990 & 75 & 106 & 79 & 215 \\
\hline 2000 & 94 & 67 & 83 & 402 \\
\hline
\end{tabular}

Note: for all countries the income figures for the years specified are used in combination with internal distribution figures for the nearest available year (see Appendix note).

Sources: World Bank 2002a and 2002b (for income in all three years and for distribution in latest year);

Deininger and Squire 1996 (for distribution in 1980 and 1990)

These figures show that the poor in China have become somewhat less poor in relation to the rich of the United States during the last two decades, the poor of India have fluctuated and are now marginally less relatively poor; the poor of Brazil are twice as relatively poor as in 1980 and those of Nigeria between two and three times as relatively poor. Whatever the overall single measures of distribution show, these figures dramatically underline how behind global figures is a complex and contradictory process of convergence and divergence. It is worth noting that, on the same method of calculation between 1990 and 2000 the highest quintile in China overtook the lowest quintile of the United States in level of income per head.

The same process is illustrated by the evolution of the income of the richest United States quintile and the world mean and median income, shown in Table 13. The data for this is identical to that used in the hybrid study (see Section 10).

Table 13: Relation of the top United States incomes to the world median and mean

\begin{tabular}{|l|r|r|r|}
\hline & \multicolumn{1}{|l|}{1980} & 1990 & \multicolumn{1}{|l|}{2000} \\
\hline US top quintile/world median & 34 & 31 & 26 \\
\hline US top quintile/world mean & 8.5 & 9.5 & 10.5 \\
\hline World mean/world median & 4.0 & 3.3 & 2.5 \\
\hline
\end{tabular}

Source: see Table 13

\section{Agreements and disagreements}

The above comparisons of various studies, using different methodology and data, lead to a number of tentative conclusions. First, several estimates, using partially differing 
data and methods, all place the global Gini coefficient in the 1990 as about 0.65 or a little below. It is possible that that is not a coincidence but approximates to its real value. If so, then it allows the conclusion that the distribution of income among the world's population is more unequal than for any individual country, even Brazil or South Africa which are symbols of inequality.

Second, in relation to trend, the estimates of Milanovic seem to show a very different picture from the others, though no exact comparison is possible. While the years compared are not the same, this study in finding a sharp increase in global inequality between 1988 and 1993 seem to be quite inconsistent with my calculation and that of Bourguignon and Morrison, although the latter authors rather inexplicably say that they regard the Milanovic study as consistent with theirs. But if they are incompatible, as I suspect, the reason for the difference must be the difference in the data. Milanovic and Dikhanov and Ward use the World Bank's data set on household spending while Bourguignon and Morrison, Sala-i-Martin and I use estimates of GDP per head, weighted by distribution estimates. If it is indeed this difference in income data which produces such apparently radically different results, then the debate about calculated results should obviously be replaced by a much more detailed one about the validity of these household spending estimates as compared with GDP estimates (a question which Milanovic addresses in his article (2002)). One obvious question relating to this is that of government income and spending. Total household spending will necessarily be less than total national income and a major source of the difference will be government spending. If government spending is inegalitarian then the GDP figures will

underestimate the degree of inequality; if it is egalitarian then the calculations based on household spending will exaggerate the degree of inequality. Until this kind of question has been resolved the present disagreements between different economists about the trend of global inequality in the last 20 years cannot resolve very much. The differences are really differences about the data and its appropriateness.

Third, the studies present a range of different outcomes for the last two decades of the twentieth century. Together they cast doubt on the idea that inequality has sharply and unambiguously declined during the epoch of neoliberalism. Nor do they seem to offer comfort to those who claim that it has sharply and unambiguously increased.

Fourth, it is striking that the most recent version of Maddison's widely used historical income estimates does not show the considerable decline in the Gini coefficient which was noted in the earlier version. In fact, in the whole world excluding China, there was a substantial rise in the Gini coefficient between 1980 and 1998 (which does not show up using PWT or World Bank ppp figures). This implies, in the case of Maddison, that the changes in income in China over these two decades have been a powerful producer of greater equality on a world scale, in spite of the fact that they have produced more inequality in China. This conclusion is doubly ironic when compared with that of Milanovic. He emphasises that growing inequality between rural and urban China (which he includes as two separate countries in his calculations) is one of the main factors which between 1988 and 1993 produced a sharp increase in global inequality. There is a major contradiction implicit in all this which would merit some further research. 
Fifth, calculations based on ppp estimates give lower estimates of inequality and show slower growth of inequality than estimates which convert national incomes using exchange rates. I have given data in exchange rate based-comparisons only for comparative purposes because they are so widely quoted. In my opinion an estimate of world distribution, inter-national or global, in exchange rate terms is in principle meaningless and should never be done. To give an example: between 1999 and 2001 the Euro/US Dollar exchange rate fell by around 30 percent. Does that mean that US real incomes have risen 30 percent compared with European real incomes? Evidently not. Calculations in exchange rate terms should really be banished from this debate. But they will persist because they fuel conclusions which many people want to reach. This is not to say that ppp estimates are anywhere near perfect. They have many defects. Different sources provide widely different estimates and they can only be produced by devoting a large quantity of resources to the necessary price surveys. But at least they provide in principle a coherent basis of comparison. We cannot say as much of exchange rate based estimates, especially in a world of greater exchange rate instability.

Sixth, my own calculations suggest that inequality is growing between the extremes of rich and poor while the intermediate sections of the world population move close together (see section 9). This result is consistent with a similar one produced by Melchior (2001) using annual inter-country income data.

Seventh, in comparing all these results an important debate has emerged about whether the world is characterised increasingly by a bi-modal or a uni-modal distribution. Quah has argued that what has been emerging is a "twin-peaks" form of distribution. Milanovic (2002b) also concludes that we are approaching a "world without a middle class". Applying to the world the rule of thumb that the middle class is statistically defined as those with between 75 and 125 percent of the median income he calculates than only 14.5 percent of the population belong to it. According to Maddison's figures it was only about 12 percent in 1998, scarcely changed since 1980. By contrast, Sala-i-Martin concludes that the situation is one of "vanishing twin-peaks" and "emergence of a world middle class". Not only is this difference important in relation to interpreting the statistics, but also it is relevant to the kind of class structure a more globalized capitalist world is assuming, and this would, of course, have many implications for future political development. There is plenty of scope for more work and debate on this issue both on the statistical and the political plane.

\section{Ironies of the debate}

The end of the twentieth century has produced a spate of economic assessments of it by scholars and by international institutions. While there is much agreement, except among ecological economists, that the century has been extraordinarily successful in terms of increased productivity and output, there is more doubt about the question of distribution. Many are worried that it has been a century of divergence rather than convergence. The fact that the gap between the incomes per head of countries has 
widened during the century has been observed in reports from the UNDP, the OECD, the IMF, the World Bank and other institutions and publications.

A little over a decade ago the UNDP began to denounce the use of conventional national income per head figures as an appropriate measure of development. In inventing its influential Human Development Index it argued that income per head should be converted at purchasing power parity not with exchange rates, that its value should be sharply attenuated (by using its logarithm rather than actual value) and that it should be only one third of an index of development, the other two thirds being life expectancy and education. This index, however, produces a world in which countries are considerably more quantitatively equal than when they are compared using conventional income per head. And a recent study has shown that over the long period, during which they have diverged according to income per head, they have converged according to the HDI (Crafts 2000). Bourguignon and Morrison also look not only at the long-term divergence of distribution of income but also at the convergence of the distribution of years of life. On this variable only inter-country data are available. But like income, life expectancy is unequally distributed within national populations (Sutcliffe 2001) although there is generally still very little data about this.

During the 1990s the UNDP continues to publish the HDI but puts growing propagandistic importance on measures of world inequality during the last 30 years based on figures which its reports (and most economists) had previously claimed was inappropriate - namely income per head converted into dollars using the current exchange rate. These, of course, showed sharply increasing income inequality and the UNDP's claims on this subject have been central to the spread of this idea. This irony has recently been compounded since in the late 1990s the relation between exchange rate conversions and ppp measures went partially into reverse. For example, between 1995 and 2000, due to a reverse in exchange rate trends, the ratio of the richest to the poorest 10 percent of the population (based on population-weighted inter-country figures) fell for the exchange rate comparison and rose for the ppp based comparison, the opposite of the relation which had existed in previous years and which had been exploited by those who wished to overstate inequality.

At the turn of the century the IMF, disturbed that its upbeat assessment of the twentieth century was tainted by the rise in inequality, suddenly discovered in the 2000 issue of its Global Economic Outlook that maybe income is not the most important measure of welfare and that the Human Development Index may be a better measure to use.

The UNDP and many other participants in the debate (some of them innocently) make liberal use of statistics which almost everyone (including themselves) otherwise reject as seriously misleading measures of comparative welfare of development, only, it seems, because they show inequality which is quantitatively greater and growing faster. The UNDP have been criticised for it by members of the UN Statistical Commission. And the IMF extols the convergence suggested by the HDI without mentioning that, because of the way in which the index is constructed (with a maximum attainable level and based on variables which have upper limits which most developed countries are close to), it is almost bound to show convergence. In the HDI all progress, however slow 
or rapid, expresses itself as convergence. The important discussion of world inequality therefore is being seriously harmed by uncritical and opportunistic use of statistics by these organizations.

The tendency to choose the figures which best suit one's conclusions is, of course, not confined to international bureaucracies. The reason for the extraordinary diffusion of the exchange rate based estimates of international distribution is that they seem to support already reached conclusions, especially that neoliberalism and globalization considerably worsen the distribution of income. The recent tendencies of global distribution are clearly difficult to establish and depend very much on the insufficiently discussed quality of different types of data. But the change in inequality over the last few decades is a comparatively trivial question compared with the actual degree of that inequality during all of the modern period. Inequality in the distribution of income in the world in the modern epoch as a whole is higher than in any previous period of world history; and it is greater than the inequality which exists in any single one of the world's component countries. Those are the important and undeniable facts. Those of us who believe that this is a manifestation of massive social injustice should not automatically deny all evidence of lessening inequality because it might weaken our argument. We should be concerned to arrive at the best and most coherent numerical estimates, whatever those may show. Unfortunately, we can be safe in the knowledge that an egalitarian world is not at hand.

\section{Bibliography}

Atkinson, Anthony B. 1999, 'Is Rising Income Inequality Inevitable? A Critique of the Transatlantic Consensus', WIDER Annual Lectures 3, Helsinki: Wider

Atkinson, Anthony B. and Andrea Brandolini 2001, 'Promise and Pitalls in the Use of "Secondary" Data-Sets: Income Inequality in OECD Countries as a Case Study', Journal of Economic Literature, Vol XXXIX, September

Boltho, Andrea y Gianni Toniolo 1999, 'Assessment: The Twentieth Century achievements, failures, lessons', Oxford Review of Economic Policy, Vol. 15, No. 4, Winter

Bourguignon, François and Christian Morrison 2001, 'Inequality among world citizens: 1820-1990', unpublished draft February

Crafts, Nicholas 2000, 'Globalization and Growth in the Twentieth Century', IMF Working Paper, WP/00/44, Washington DC: FMI

Deaton, Angus 2001, 'Counting the World's Poor: Problems and Possible Solutions' The World Bank Research Observer, vol 16 no.2, Fall (125-147); also comments by Martin Ravallion (same reference 148-156) and by T.N.Srinivasan (157-168)

Deininger, Klaus and Lyn Squire 1996, "A new data set measuring income inequality", World Bank, (http://www.worldbank.org/html/rdmg/grwthweb/ growth_t.htm)

Dikhanov, Yuri and Michael Ward 2001, 'Measuring the distribution of global income', World Bank research document, unpublished

Firebaugh, Glenn 1999, 'Empirics of World Income Inequality', American Journal of Sociology Vol 104, Number 6 May (1597-1630) 
Heston, Alan, Robert Summers and Bettina Aten 2001, Penn World Table Version 6.1, Center for International Comparisons at the University of Pennsylvania (CICUP), December

International Monetary Fund, World Economic Outlook, Washington DC: IMF

Kanbur, Ravi 2001, 'Economic Policy, Distribution and Poverty: the Nature of Disagreements', World Development, vol. 29, no. 6, 1083-1094

Jolly, Richard 1999, 'Global Inequality', Wider Angle, December

Lustig, Nora y Ravi Kanbur 1999, 'Why is inequality back on the agenda' paper for Annual Bank Conference on Development Economics, Washington DC: World Bank, April

Maddison, Angus 2001, The World Economy: a millenial perspective, OECD.

Melchior, Arne 2001, 'Global income inequality: beliefs, facts and unresolved issues', World Economics, Vol 2 No 3 July-September

Melchior, Arne and Djetil Telle 2001, 'Global Income Distribution 1965-98: Convergence and Marginalisation' Forum for Development Studies No 1

Melchior, Arne, Kjetil Telle and GenrikWiig 2000, 'Globalisation and Inequality: World Income Distribution and Living Standards, 1960-1998', Royal Norwegian Ministry of Foreign Affairs, Studies on Foreign Policy Issues, Report 6B

Merrill Lynch and Cap Gemini Ernst \& Young 2002, World Wealth Report 2002, Internet document

Milanovic, Branko 2002, 'True world income distribution, 1988 and 1993: First calculation based on household surveys alone', Economic Journal 112, January

Milanovic, Branko 2002, 'Worlds Apart': International and World Inequality 1950-2000, work in progress, February (obtainable from World Bank website, Inequality)

Pritchett, Lant 1997, 'Divergence, big time', Journal of Economic Perspectives, Vol. 11, No.3, Summer

O'Rourke, Kevin 2001, “Globalization and Inequality: Historical Trends", NBER Working Paper 8339, (http://www.nber.org/papers/w8339)

Quah, D. 1996, 'Twin Peaks: Growth and convergence in Models of Distribution Dynamics', Economic Journal, July

Sala-i-Martin, Xavier 2002, 'The World Distribution of Income (estimated from individual country distributions)', NBER Working Paper 8933, (http://www.nber.org/papers/w8933)

Sala-i-Martin, Xavier 2002, The Disturbing "Rise" of Global Income Inequality, NBER Working Paper 8904, (http://www.nber.org/papers/w8904)

Schulz, T. Paul 1998, 'Inequality in the distribution of personal income in the world: How it is changing and why', Journal of Population Economics, 11, pp. 307-344

Stewart, Frances and Albert Berry 1999, "Globalization, Liberalization and Inequality: expectations and experience" (in Andrew Hurrell and Ngaire Woods, Inequality, globalization and World Politics, Oxford: Oxford University Press.

Summers, Robert and Alan Heston 199?, 'The World Distribution of Well-being Dissected', in Alan Heston and Robert E. Lipsey (editores), International and Interarea Comparisons of Income, Output, and Prices, NBER: Studies in Income and Wealth, Volume 61

Sutcliffe, Bob 2001, 100 ways of seeing an unequal world, London: Zed Books. UNDP 1999, Human Development Report 1999, Oxford: Oxford University Press.

Wade, Robert 2001, Global inequality: winners and losers', The Economist, April 28 
Williamson, Jeffrey G. 1997, 'Globalization and inequality: past and present', World Bank Research Observer, Volume 12, No.2, August

Williamson, Jeffrey G. and Peter Lindhert 2001, "Does globalization make the world more unequal?", in Michael D. Bordo, Alan Taylor and Jeffrey G. Williamson (editors), National Bureau of Economic Research, Globalization in Historical Perspective, conference volume, forthcoming (also available as NBER Working Paper No. 8228, 2001)

Wolf, Martin 2000, "The big lie of global inequality", Financial Times, 9 February

World Bank, "Income poverty: the latest global numbers", 2001 http://www.worldbank.org/poverty/data/trends/income.htm

World Bank 2002a, World Development Indicators 2002 online version, Washington DC: World Bank

World Bank 2002a, World Development Indicators 2002 book version, Washington DC: World Bank 
Appendix note

Countries in my "pure" study with exact dates of distribution estimates:

First year

Australia

79

Second year

Bangladesh

78

Brazil

80

Bulgaria

80

Canada

79

90

86

Third year

China

80

Colombia

78

Costa Rica

81

Czech Rep/Czecho.

80

Dominican Rep

84

France

79

Greece

81

Hungary

India

77

77

89

94

Indonesia

80

90

$95 / 6$

Italy

80

Jamaica

75

Jordan

80

Korea Rep (South)

80

Malaysia

79

90

98

Mexico

77

Morocco

Netherlands

84

79

Nigeria

86

Norway

79

Pakistan

79

Panama

Poland

Portugal

79

80

80

90

97

94

$88 \quad 96$

$89 \quad 97$

$88 \quad 96$

$89 \quad 98$

$84 \quad 95$

$88 \quad 93$

$89 \quad 98$

$90 \quad 97$

Russian Fed/USSR

80

90

99

$89 \quad 95$

$90 \quad 00$

$91 \quad 97$

$88 \quad 93$

$89 \quad 97$

Sri Lanka

80

Thailand

75

89

98

91

$98 / 9$

91

92

94

Turkey

73

91

88

$96 / 7$

USA

80

Venezuela

79

89

95

$96 / 7$

97

90

90

98

89

$94 / 5$

90

98

90

95

87

98

90

94

97

Share of world pop $\quad 70$

Share of world GDP

61

90

98

Sources: Deininger and Squire, World Bank 2002b 